\title{
Factors associated with COVID-19 test willingness in Indonesia: tele-survey study after 'new normal' policy in risk groups
}

\author{
Mutiara Widawati ${ }^{1,2^{*}}$, Firda Yanuar Pradani $^{1}$, M. Ezza Azmi Fuadiyah ${ }^{1}$, Hubullah Fuadzy ${ }^{1}$, and \\ Rohmansyah W. Nurindra ${ }^{1}$ \\ ${ }^{1}$ Pangandaran Health Research and Development Center, National Institute of Health Research and Development, Ministry of \\ Health of Indonesia, Pangandaran KM. 3, Babakan, Kabupaten Pangandaran \\ ${ }^{2}$ School of Public Health, Edward Ford Building, A27 Fisher Rd, University of Sydney NSW 2006, Australia
}

\begin{abstract}
Data about testing for COVID-19 is important to be recognized since disease diagnostic tests are useful as a foundation for various purposes. Therefore, to obtain comprehensive data regarding the willingness of the Indonesian people to test for COVID-19, a study was carried out. This study is a population-based quantitative study with a cross-sectional design conducted on risk groups located in Pangandaran Regency, Indonesia in 2020. Data collection used a tele-survey technique (telephone interview) with a closed electronic questionnaire instrument. and 400 people as samples. A multivariate analysis was applied between factors such as age group, gender, income, confirmed COVID-19 environment, intensity of information seeking, social media exposure, and willingness to test for COVID-19. The results showed that there were more respondents who stated they did not want to take the COVID-19 test than those who did. The majority of respondents stated that the reason for not wanting to take the COVID-19 test was because they felt it was unnecessary and considered expensive. This study also shows that factors such as the latest level of education, monthly income before the new normal, confirmed COVID-19 environment, intensity of information seeking, and exposure to social media have the potential to affect willingness to test for COVID-19.
\end{abstract}

\section{Introduction}

COVID-19, a disease caused by the novel coronavirus (Severe Acute Respiratory Syndrome Coronavirus 2, [SARS-CoV-2]) is rapidly spreading and affecting 216 countries worldwide. This disease already infected 98 million people and caused death to 1.9 million people. [1] Approximately all world's population is at risk of COVID-19 infection, and Indonesia is one of them. This country already has 836,718 positive COVID19 cases and 24,343 deaths because of it. [2] Indonesia is one of the countries with the fastest COVID-19 infection rate in Asia. During this situation, the World Health Organization (WHO) advised every country to implement multiplication of the COVID-19 confirmation test [3] to produce more appropriate and efficient disease control.

The increasing number of COVID-19 cases in Indonesia shows that the control and prevention implemented in Indonesia are not effective enough to overcome the fast rate of this disease spread. Recently, the COVID-19 vaccine has been approved to be included in several countries' health programs including Indonesia. The government has launched a gradual provision of vaccines for all Indonesian citizens. [4] Despite the vaccine launching, vaccines do not necessarily eliminate this disease in a short time, especially by taking into account the uncertainty of public acceptance of vaccines due to various media attacks published by anti-vaccines and distrust spread by social media. [5]

Besides the vaccine, another effort implemented by the Indonesian government to deal with this disease is the implementation of the Large-Scale Social Restriction (PSBB) policy in early 2020. This effort is aimed to reduce the spread of COVID-19 by maintaining distance between individuals. This effort is thought to be more realistic to be implemented in Indonesia compared to the 'lockdown' efforts which have been done in other countries because these efforts still allow people's economic activities to be held as long as they applied health protocol. [6] After several months of implementing the PSBB, the Indonesian government began implementing a new policy called AKB (New Normal Adaptation). During this period, the government permitted people to perform several activities (which previously were not allowed) under certain conditions. [7] The implementation of a new, "weaker" policy more

\footnotetext{
*Corresponding author: mutiarawidawati@litbang.kemkes.go.id
} 
likely gave an impact on people's willingness to be tested and if it goes wrong, then it could lead to the second wave of disease spread. [8]

The COVID-19 test is an initial step to control the spread of this disease. [9] The awareness of individuals who knows that they have COVID-19 will make them take more active prevention of transmission than individuals who do not know about it. Furthermore, this test can also be used as an asymptomatic transmission in population overview for the government and the community. [10] The delay in public and Indonesian government awareness of the COVID-19 test at the start of the pandemic is probably one of the reasons why some studies doubt the incidence of COVID-19 in Indonesia. $[11,12]$ Although now Indonesia has performed widespread PCR testing by utilizing the coordination of various institutions, the total number of tests performed is not sufficient to describe the actual conditions occurring in Indonesia. [12]

Until recently, the most accurate test recommended determining a person's COVID-19 status is still the PCR test. [13] A person's willingness for a PCR test can be influenced by many things. Indonesia and other lowermiddle-income countries residents would not think that taking a paid PCR test is such an easy matter. The high cost is likely to affect the willingness of both the government and the community, let alone wishing that the community will carry out this test independently without government assistance. Studies conducted by Grossman and Van der Weele show that ignorance in society might emerge towards positive actions when those actions are high cost. [14]

Other possibilities can also influence people's willingness to take the PCR test as a confirmation test for COVID-19. Individual characteristics are one of them. Characteristics of a person can influence their behaviour and their viewpoint on a disease. Information circulating in the community is also one of the factors that can influence society's willingness. The government needs to develop a strategy to optimize communication with the public regarding the risk of infectious diseases so that the various factors that cause negative behaviour towards diseases circulating in the community can be mitigated. [10]

So far, there are very limited articles discussing the willingness to take a disease prevention effort that involve the willingness to pay in Indonesia [15] and as far as we know, there has been no study that specifically addresses the willingness for a COVID-19 disease test in Indonesian residents. It is important to acknowledge that data about disease diagnostic tests are useful as a foundation for various purposes. Therefore, to acquire comprehensive data regarding the COVID-19 test willingness of Indonesian people, a study has been conducted. This study underlines factors that might influence a person, who are at high risk of COVID-19, to be willing to test for COVID-19 independently in a developing country like Indonesia. The data in this study will be very useful as a foundation for the government to create policies that can support the widespread COVID-19 test for all Indonesians. In the future, this study can also be used as a basis for policies that can support initial diagnostic testing to prevent other diseases.

\section{Methodology}

This study is a part of the project titled "Information Seeking Behaviour and Covid-19 Prevention Measures in Risk Groups during AKB (Adaptation to New Normal)". [16] This research is a quantitative population-based study with a cross-sectional design. The research was conducted from October to December 2020 and was conducted in Pangandaran district, west java province, Indonesia.

The study population was taken from the data of people who were at high risk of contracting COVID-19 listed in the Pangandaran District Health Office and the Pangandaran Regional Health Laboratory. The high-risk community population consists of tourism personnel (Pangandaran residents who are involved in the tourism sector), crowd subjects (Pangandaran residents taken in crowded places), health workers (Pangandaran residents who are health workers), religious leaders (Pangandaran residents who are religious figures such as the head of the pesantren (moslem's religious school) or the teacher of the pesantren), and people who had close contact with the patient confirmed positive for Covid-19. The total population obtained was 3923 people. The sample size is calculated using the sample calculation formula for the randomized stratified sampling method. [17] The sampling method is used considering the proportion of each risk group. The sample size obtained was 400 people. To anticipate sample shortages due to exclusion criteria, the same sample calculation was used to select 150 people as a sample reserve.

Ethical approval was provided by the Ethical Committee for Health Research, National Institute of Health Research and Development, the Ministry of Health of Indonesia (Number: LB.02.01/2/KE.553/2020). The data was collected using a tele-survey technique (telephone interview) with a closed-ended electronic questionnaire as an instrument. Interviews were conducted by trained data collectors. Every participant was informed about and understood the purpose of our investigation before entering the study. Before being interviewed, each participant was asked for their consent to participate in this research. Approval is obtained from each respondent without coercion and the respondent can pull out their consent at any time. Respondents who refused, resigned, disconnected, could not be contacted again during telephone interviews, came from outside the Pangandaran district, as well as respondents who were less than 17 years old were excluded from this study sample and replaced with respondents who had been prepared from the reserve. Consent from parents or guardians of those participants aged under 18 was not required. This has been approved by the Ethical Committee for Health Research, National Institute of Health Research and Development, the Ministry of Health of Indonesia.

This research instrument was made based on the framework of the CMIS (Comprehensive Model of 
Information Seeking) model [18] and Theory of Planned Behaviour. [19] The questionnaire contains close-ended and multiple-choice questions which are designed to be as simple as possible to be filled. Before being used in data collection, the reliability test was carried out on 30 people using the questionnaire prepared. The questionnaire was revised and retested until the reliability coefficient (Cronbach alpha) was $0.655(>0.5)$. The data in the preliminary test were not included in the final analysis.

To acquire comprehensive data regarding the description of respondents who did not want the COVID19 to test independently, respondents were also given open questions regarding the reasons why they did not want to take the COVID-19 test independently. The same answers are grouped and then the percentage of all respondents is made. Multivariate analysis was performed using logistic regression with backward Wald method to determine the relationship of the response variable (willingness to test) and each explanatory variable (age group, gender, education, income before the 'new normal' period, intensity of information seeking, and social media exposure). The relationship between variables is described by the value of the Odd ratio (OR) along with the value of the confidence interval $(95 \% \mathrm{CI})$. The analysis is carried out to find the most optimal equation model. The difference in OR $>10 \%$ between the previous model and the model after the variable was removed is used to determine whether the variable can be included in the final model or not. All data were analysed using SPSS version 15 (IBM Inc., Chicago, IL.USA).

\section{Findings}

The results of the logistic regression analysis quantifying the effect of various factors on willingness to do tests independently are presented in table 1. Based on multivariable analysis, predictors of willingness to do test independently were last education level, income per month before new normal, positive COVID-19 neighbourhood, Information seeking intensity, and social media exposure. While age group and gender did not significantly affect the response variable.

Table 1. Factors that influence people to get vaccinated

\begin{tabular}{|c|c|c|c|c|c|}
\hline \multirow[t]{2}{*}{ Factors } & \multicolumn{2}{|c|}{ Test willingness } & \multirow[t]{2}{*}{ OR } & \multirow[t]{2}{*}{$95 \% \mathrm{CI}$} & \multirow[t]{2}{*}{ p-value } \\
\hline & Yes $(\%)$ & No (\%) & & & \\
\hline Age groups & & & & & 0.178 \\
\hline$<21$ years old & 0.8 & 3.5 & NA & NA & NA \\
\hline 21 - 40 years old & 13.3 & 45.8 & NA & NA & NA \\
\hline $41-60$ years old & 6.3 & 25.5 & NA & NA & NA \\
\hline$>60$ years old & 1.5 & 3.5 & NA & NA & NA \\
\hline Gender & & & & & 0.125 \\
\hline Men & 11.3 & 50.0 & NA & NA & NA \\
\hline Women & 10.5 & 28.3 & NA & NA & NA \\
\hline Last education level & & & & & 0.033 \\
\hline Elementary & 1.5 & 10.3 & 0.480 & $0.172-1.336$ & 0.160 \\
\hline High school & 7.8 & 47.5 & 0.455 & $0.248-0.835$ & 0.011 \\
\hline University/college & 12.5 & 20.5 & 1 & & \\
\hline Income per month & & & & & 0.009 \\
\hline$<\operatorname{Rp} 2$ million & 7.3 & 46.5 & 0.311 & $0.117-0.826$ & 0.160 \\
\hline Rp 2-5 million & 11.3 & 28.0 & 0.696 & $0.274-1.772$ & 0.448 \\
\hline$>\mathrm{Rp} 5$ million & 3.3 & 3.8 & 1 & & \\
\hline Positive COVID-19 neighborhood & & & & & $<0.001$ \\
\hline Yes & 5.0 & 5.8 & 4.369 & $2.055-9.289$ & $<0.001$ \\
\hline No & 16.8 & 72.5 & 1 & & \\
\hline Information seeking intensity & & & & & 0.005 \\
\hline Rarely & 7.5 & 47.5 & 0.354 & $0.189-0.663$ & 0.001 \\
\hline Sometimes & 3.3 & 11.8 & 0.465 & $0.204-1.058$ & 0.068 \\
\hline Often & 11.0 & 19.0 & 1 & & \\
\hline Social media exposure & & & & & 0,016 \\
\hline Often & 12.3 & 35.5 & 2.035 & $1.143-3.625$ & 0,016 \\
\hline Not often & 9.5 & 42.8 & 1 & & \\
\hline
\end{tabular}

NA: Not Applicable (were not included in the multivariate analysis)

Table 1 showed that respondents who have university/college degree education tend to be more willing to do the test independently compared to the ones who have lower degrees of education. High school level of education respondents is 0.455 times less likely to be willing to do the test compared to the one who has 
university level of education $(\mathrm{CI}=0.248-0.835 ; \mathrm{p}=0.011)$. Elementary school level of education respondents is 0.480 times less likely to be willing to do so as well $(\mathrm{CI}=0.172$ 1.336; $\mathrm{p}=0.160$ ).

The result also showed that respondents who have an income higher than 5 million IDR tend to be more willing to do the test independently compared to the ones who have a lower monthly income. Respondents who have a monthly income of less than 2 million IDR are 0.311 times less likely to be willing to do the test compared to the ones who have the highest salary $(\mathrm{CI}=0,117-0.826$; $\mathrm{p}=0.160)$. Similar to the lower salary, respondents who have a monthly income between 2 million and 5 million are 0.696 times less likely to be willing to do the test compared to the ones who have the highest salary $(\mathrm{CI}=0.274-1.772 ; \mathrm{p}=0.448)$.

Respondents who have positive COVID-19 neighbours are 4.369 times more likely to be willing to do the test compared to the one who does not have it $(\mathrm{CI}=$ 2.055-9.289; $\mathrm{p}<0.001)$. Similar to this behaviour, respondents who often got information from social media are 2.035 times more likely to be willing to do the test independently compared to those who do not often get it $(\mathrm{CI}=1.143-3.625 ; \mathrm{p}=0.016)$.

The results also showed that respondents who rarely seek information about COVID-19 tend to have lower test willingness (0.354 times) compared to the ones who often seek it $(\mathrm{CI}=0.189-0.663 ; \mathrm{p}=0.001)$. Similar to this, respondents who seek information 'sometimes' also tend to have lower test willingness ( 0.465 times) compared to the ones who often seek it $(\mathrm{CI}=0.204-1.058 ; \mathrm{p}=0.068)$.

Table 2 shows an overview of the reasons for respondents who did not want to take the COVID-19 test independently. More respondents stated that they did not want to take the COVID-19 test $(78.5 \%)$ than those who did. The majority of respondents answered that the reason they did not want to take the COVID-19 test was that they felt it is unnecessary $(49.75 \%)$. In addition, the second largest answer related to reasons for not wanting to be tested was because the COVID-19 test was considered expensive $(17.5 \%)$.

Tabel 2. Reasons that influence people to get vaccinated

\begin{tabular}{|l|c|c|}
\hline \multicolumn{1}{|c|}{ Reasons } & Total & $\begin{array}{c}\text { Percentage of all } \\
\text { respondents (\%) }\end{array}$ \\
\hline Unnecessary & 199 & 49.75 \\
\hline Expensive & 70 & 17.5 \\
\hline Afraid to be tested & 33 & 8.25 \\
\hline $\begin{array}{l}\text { Don't understand anything } \\
\text { about the COVID-19 test }\end{array}$ & 10 & 2.5 \\
\hline $\begin{array}{l}\text { The test place distance is } \\
\text { too far }\end{array}$ & 1 & 0.25 \\
\hline $\begin{array}{l}\text { Later, if I got close contact } \\
\text { with the COVID-19 } \\
\text { confirmed case }\end{array}$ & 1 & 0.25 \\
\hline \multicolumn{1}{|c|}{ Total } & 314 & 78.5 \\
\hline
\end{tabular}

\section{Discussion}

This study is inseparable from several limitations. This research was conducted using a closed questionnaire so that the answers given by respondents were not explored further. There is a possibility that there will be hypothesis bias because the analysis is based on survey data. Respondents can answer the survey with a different answer from what they did. This bias is common in studies that measure a person's positive behaviour [20] Besides hypothetical bias, this study also does not describe Indonesia as a whole. This study was conducted in only one district in Indonesia and does not necessarily represent the whole of Indonesian society, especially since this study was conducted in the Pangandaran district that still consists of many villages. Certainly, the individual characteristics will be somewhat different from urban communities such as Jakarta (the capital city of Indonesia).

A person's willingness to take a COVID-19 test is probably caused by various factors, similar to other behavioural changes that can be influenced by several factors. Those factors include the expensive PCR test for COVID-19, changes in policies implemented by the government, anxiety, concern, boredom due to continuous exposure to information [21], socio-demographic characteristics [22], social norms [23], informationseeking behaviour, facility availability, and other factors. $[10,24]$

The results in this study indicate that the majority of respondents do not want to take the COVID-19 test because they feel it is unnecessary and they feel that the COVID-19 test is expensive. The minimum costs incurred for taking one test is 900,000 IDR (equivalent to 60 USD) [25], in addition, costs can also be incurred during selfisolation which is a direct effect of the COVID-19 test if the test results are positive. [10] This research shows that the majority of respondents have an income of less than 2 million IDR (equivalent to around 140 USD) per month, and indeed to spend 60 USD per test will be quite difficult for people with this income. As shown in the results, income is one of the factors of individual characteristics that has a significant effect on a person's willingness to take a COVID-19 test. Respondents who have a monthly income of less than 5 million IDR (equivalent to 340 USD) are more likely to refuse to do a COVID-19 test than respondents who have an income of more than 5 million.

Another factor that can influence behavioural change is individual characteristics. [22,26] This study result showed that the individual characteristics, which are the level of education and income, influenced the willingness of the COVID-19 test. Similar conclusions have been drawn from other studies in Pakistan. [22] This is probably because individuals with higher education have a greater tendency to increase knowledge related to disease risk and have a higher probability to digest information from health promotion. Therefore, prevention efforts can be more adapted to their daily lives. The insignificance association between the willingness to test for COVID-19 and ages or genders is probably because the will tends to be random across all ages and genders, so these factors have no effect on this behaviour.

The low percentage of respondents who want to take a COVID-19 test after the new normal period might also be because the community is bored and tired of taking prolonged prevention. Several studies state that prolonged 
intervention is one of the challenges that may occur in a community and can cause psychological fatigue of the individual that affects the practice they would take. $[21,27]$ The low willingness for a COVID-19 test may also be because respondents choose not to care and choose to avoid information by hardly seeking it. This information-seeking ignorance behaviour is also demonstrated by a study done by Grossman. [28] The rarity of individuals who seeks information about COVID-19 in this study might also be explained by previous research that suggests if a person already knows their medical diagnosis and knows that this diagnosis is important as their basis for improving their health behavior, there is still the possibility that they will consciously do not care about it. [10,29]

The level of public compliance to health recommendations in several places in Indonesia is still in question. Several studies conducted in various regions in Indonesia have shown that the level of community compliance tends to be less than good, moreover, there is one study that reported that the disinfection activities carried out by people who should know health protocols is have not met the correct standard of health protocols. [30,31] In contrast to several countries that have implemented penalties due to violations of COVID-19 prevention protocol standard [32], penalties due to COVID-19 prevention violations are not discussed both in PSBB and AKB policies. The light penalty is only applied by a few regions depending on the local policies applied there, and still, it did not show a significant impact on public compliance in Indonesia. [33]

This study shows that although the number of individuals who frequently seek information is less than those who rarely do it, the ones who frequently seek information are more likely to be willing to take the COVID-19 test compared to the ones who rarely seek it. It might be due to their concern which was affected by the high intensity of information seeking that they performed. [34]

Respondents who frequently access social media are also more likely to be willing to take tests than those who do not. A large number of social media usage by people as a form of their concern for COVID-19 was also reported by descriptive research conducted in China. [35] Probably people feel that it is a necessity to look for news related to cases of an infectious disease. News related to the number of cases is a topic that can help people to be more aware of the disease. Furthermore, information related to the topic of disease epidemiology can also help people in promoting disease prevention and control for their families and their social life. [36] This is also supported by the results which show that respondents whose aware of their positive COVID-19 neighbours were more likely to have a will in the COVID-19 test compared to respondents who do not. This study also shows that the more exposed someone is to information, the more prudent his subconscious will be, which will lead to curiosity to get more information. The amount of information obtained can cause concern and a willingness to change behaviour.

Hopefully, the result of this study is going to be useful for the government in developing countries such as
Indonesia. It can be used as a foundation and complement for the body of literature in formulating policies to support COVID-19 widespread testing for all populations. The various factors presented can be used as the base data to achieve a focused and compatible connection between health promotion intervention and the population targets. Both individuals who have a will for testing and those who have not might be directed toward more positive behaviour.

\section{Conclusion}

This study concludes that the number of people who did not want to be tested for COVID-19 is greater than the number of people who did want to be tested for COVID19. The majority of respondents' reason why they did not want to take the COVID-19 test was that they felt it was unnecessary and the test was considered expensive. This research also shows that risk factors such as last education level, income per month before new-normal policy, positive COVID-19 neighbourhood, information seeking intensity, and social media exposure are related and have the potential to influence the willingness for a COVID-19 test.

The author would like to thank the Pangandaran District Health Office, Pangandaran Health Laboratory, and all staff of the Pangandaran Health Research and Development Unit for their assistance in conducting this research. I would also like to thank Firda Yanuar Pradani for her guidance in this research and in the process of writing this paper.

\section{References}

1. World Health Organization (WHO). Coronavirus disease (COVID-2019) situation reports. https://www.who.int/docs/default-

source/coronaviruse/situation-reports (accessed on 10 of January 2021). (2021).

2. Task Force for the Acceleration of Handling COVID19. The situation of the COVID-19 virus in Indonesia. Indonesia; (2020).

3. World Health Organization (WHO). WHO DirectorGeneral's opening remarks at the media briefing on COVID-19. Media briefing on COVID-19. (2020).

4. Presidential Decree No. 14 of 2021 concerning Vaccine Procurement and Vaccination Implementation in the Context of Combating the 2019 Corona Virus Disease (Covid-19) Pandemic. (2021).

5. R. Rahayu. COVID19 Vaccine in Indonesia: Analysis of Hoax News. J Econo Sauce Hum [Internet]. 2021;2(7):39-49. Available from: https:// www.jurnalintelektiva.com/index.php/jurnal/article/ view/422. (2021).

6. A Roziqin, Mas'udi S, Sihidi I. An analysis of Indonesian government policies against COVID-19. Public Adm Policy An Asia-Pacific J. 2021;

7. WHO Indonesia. COVID-19 Indonesia Situation Reports. 2020. (2020). 
8. Xu S, Li Y. Beware of the second wave of COVID19. Lancet. 2020;395(10233):1321-2.

9. MW. Seeger. Best practices in crisis communication: an expert panel process. J Appl Commun Res.34(3):232-44. (2006).

10. L. Thunström, M. Ashworth, J. Shogren, S. Newbold, Finnoff D. Testing for COVID-19: Willful ignorance or selfless behavior? Behav Public Policy.1-8. (2020).

11. P. De Salazar, R. Niehus, A. Taylor, C. Buckee, M Lipsitch. Using predicted imports of 2019-nCoV Cases to determine locations that may not be identifying all imported cases. medRxiv. (2020).

12. R. Djalante, J. Lassa, D. Setiamarga, A. Sudjatma, M .Indrawan, B. Haryanto, et al. Review and analysis of current responses to COVID-19 in Indonesia: Period of January to March 2020.

13. Centers for Disease Control and Prevention. Guidance for Health Departments about COVID-19 Testing in the Community [Internet]. 2019 [cited 2021 Apr 21]. Available from: https://www.cdc.gov/coronavirus/2019ncov/php/testing.html

14. Z. Grossman, J. van der Weele. Self-image and willful ignorance in social decisions. J Eur Econ Assoc.15(1):173-217. (2017).

15. H. Harapan, S. Anwar, A. Bustamam, A. Radiansyah, P. Angraini, R. Fasli, et al. Willingness to pay for a dengue vaccine and its associated determinants in Indonesia: a community-based, cross-sectional survey in Aceh. Acta Trop.;166:249-56. (2017).

16. Pradani FY, Widawati M, Fuadiyah MEA, et al. Research Report Information seeking behavior and COVID-19 preventive measures in at-risk groups during new normal period (Adaptation of New Habits). Pangandaran; (2020).

17. ER. Ziegel, Lemeshow S, D. Hosmer, J. Klar, S. Luanga. Adequacy of Sample Size in Health Studies [Internet].36, Technometrics. 232. Available from: https://apps.who.int/iris/handle/10665/41607.(1994).

18. JD. Johnson, J. David Johnson, WA. Donohue, CK. Atkin,S. Johnson. A Comprehensive Model of Information Seeking. 16, Science Communication. 274-303. (1995).

19. NA Flanders, M Fishbein, I Ajzen. Belief, Attitude, Intention, and Behavior: An Introduction to Theory and Research. Addison-Wesley; (1975).

20. N Jacquemet, R V Joule., S Luchini, JF Shogren. Preference elicitation under oath. J Environ Econ Manage.65(1):110-32. (2013).

21. O Ilesanmi, A Bello, A Afolabi. COVID-19 pandemic response fatigue in Africa: causes, consequences, and counter-measures. Pan Afr Med J.37(Suppl 1). (2020).

22. $M$ Yaseen, A Saif, $T$ Khan, $M$ Yaseen. Public knowledge and adherence to hand hygienic guidelines for the prevention of SARS-CoV-2 transmission: A cross-sectional survey from Pakistan
2021. Disaster Med Public Health Prep.;Mar:1-6. (2021).

23. RB Cialdini, NJ Goldstein. Social influence: compliance and conformity. Annu Rev Psychol.55:591-621. (2004).

24. N Nguyen, T Hoang, V Tran, Vu C, Siewe FJ, Colebunders R, et al. Preventive behavior of Vietnamese people in response to the COVID-19 pandemic. PLoS One. 202015(9):e0238830.

25. Indonesian Ministry of Health. Circular of the Ministry of Health of the Republic of Indonesia No. HK.02.02/I/3713/2020 concerning the Highest Tariff Limit for Real Time Polymerase Chain Reaction (RT-PCR) Examination. HK.02.02/I/3713/2020. (2020)

26. S Uddin, T Imam, M Khushi, A Khan, Moni M. How did socio-demographic status and personal attributes influence compliance to COVID-19 preventive behaviours during the early outbreak in Japan? Lessons for pandemic management. Pers Individ Dif.;175(June):110692. (2021).

27. M Roberts, V Andreasen, A Lloyd, L Pellis. Nine challenges for deterministic epidemic models. Epidemics.10:49-53. (2015).

28. Z Grossman. Strategic Ignorance and the Robustness of Social Preferences. Manage Sci.60(11):26592665. (2014).

29. T Sharot, CR Sunstein. How people decide what they want to know. Nat Hum Behav.;4:14-9. (2020).

30. W Wiranti, A Sriatmi, W Kusumastuti. Determinants of Depok City community compliance with largescale social restriction policies in prevention. $\mathrm{J}$ Kebijak Kesehat Indones JKKI. 9(3):117-24. (2020).

31. A Athena, E Laelasari, T Puspita. Implementation of Disinfection in Prevention of Covid-19 Transmission and Potential Health Risks in Indonesia. J Ekol Kesehat.;19(1):1-20. (2020).

32. S Rab, M Javaid, A Haleem, R Vaishya. Face masks are new normal after COVID-19 pandemic. Diabetes Metab Syndr Clin Res Rev.;14(6):1617-9. (2020).

33. Y Farhan. Implementation of Sanctions Against Violations of the Use of Masks in the Context of Preventing the Spread of COVID-19 (Analysis of the Mayor of Banda Aceh City Regulation No. 25 of 2020). ETD Unsyiah. Maret. (2021).

34. P Liu. COVID-19 information seeking on digital media and preventive behaviors: the mediation role of worry. Oct 1;23(10):677-82. Cyberpsychology, Behav Soc Netw. 2020;23(10):677-82. (2020).

35. Y Zhao, S Cheng, Yu X, Xu H. Chinese Public's Attention to the $\{$ COVID-19\} Epidemic on Social Media: Observational Descriptive Study (Preprint).

36. Gu H, Chen B, Zhu H, Jiang T, Wang X, Chen L, et al. Importance of Internet Surveillance in Public Health Emergency Control and Prevention: Evidence From a Digital Epidemiologic Study During Avian Influenza A \{H7N9\} Outbreaks.16, 20 (2021) 